\title{
Repositório de objetos de aprendizagem Kelix: uma materialização da cibercultura
}

\author{
Jonas Machado Brunetto ${ }^{1}$ \\ Adriano Canabarro Teixeira ${ }^{2}$ \\ Ana Carolina Bertoletti De Marchi ${ }^{1}$ \\ ${ }^{1}$ Curso de Ciência da Computação - Universidade de Passo Fundo (UPF) \\ ${ }^{2}$ Mestrado em Educação - Universidade de Passo Fundo (UPF)
}

$\{75979$, teixeira, carolina $\} @$ upf.br

Resumo. Em uma sociedade marcada por fortes traços de colaboração e de compartilhamento, somado ao crescimento do uso das tecnologias no nosso cotidiano, a inclusão digital ganha uma nova relevância frente a sociedade contemporânea. Dentro deste cenário surge o projeto kelix, que através da informática fornece um suporte a inclusão digital. Neste sentido, este artigo irá apresentar o processo de criação de um repositório de objetos de aprendizagem para dar suporte a um espaço efetivo de participação neste movimento de informatização.

Palavras-chave: Software Livre, Cibercultura, Inclusão Digital e Objetos de Aprendizagem

\section{Repository of learning objects Kelix: a materialization of cibercultura}

\begin{abstract}
In a society marked by strong traces of collaboration and sharing, in addition to the growing use of technology in our life, digital inclusion takes on a new relevance to contemporary society. Within this scenario comes the kelix project, which through a informatics provides support for digital inclusion. This paper presents the

process of creation learning object repository to support a space for effective participation in this movement.
\end{abstract}

Keywords: Open Source, Cyberculture, Digital Inclusion and Learning Objects.

\section{Introdução}

Na sociedade contemporânea, a utilização da tecnologia para a realização de tarefas do cotidiano já não é uma novidade. Tal transformação faz parte de um fenômeno denominado cibercultura. 
Alguns elementos potencializam esta nova organização social, entre eles podemos citar as Tecnologias de Rede (TR) que possuem um papel muito importante na manifestação plena da cibercultura. Elas pressupõem a existência de múltiplas conexões, possuindo uma perspectiva dinâmica e multidirecional, potencializando os processos de co-autoria.

Como conseqüência deste potencial de suporte a processos de autoria e coautoria, surge um fenômeno que tem como suporte as possibilidades que as TR oferecem, denominado software livre. O software livre se destaca como uma materialização do paradigma das TR, por ser uma alternativa para a criação, a colaboração, a independência tecnológica e cultural. A este movimento agrega-se o conceito de Objetos de Aprendizagem (OA), que são vistos, neste trabalho, como uma manifestação dos pressupostos da cibercultura e do próprio software livre.

Diante deste contexto e procurando se apropriar os conceitos acima, este trabalho apresenta a concepção do repositório Kelix de objetos de aprendizagem desenvolvido como um ambiente que tem como lógica organizacional a dinâmica da colaboração, da co-autoria e da inteligência coletiva.

Desta forma, neste artigo encontra-se um breve estudo sobre a cibercultura e os efeitos da tecnologia de redes no cotidiano da sociedade. Também serão apresentados os objetivos do repositório Kelix, os paradigmas que o sustentam e as tecnologias que foram utilizadas em sua construção. Por fim, algumas considerações serão apresentadas quanto à operacionalização do ambiente.

\section{As tecnologias de rede seus impactos na sociedade contemporânea.}

O cotidiano das pessoas vem sofrendo uma grande mudança provocada pelos adventos de novas tecnologias. Segundo Lemos, "A cibercultura é a cultura contemporânea marcada pelas tecnologias digitais" (2003; pp. 11-23), e, com base nesta definição, podemos supor que as transformações da sociedade, impulsionadas pelas tecnologias de rede, são uma materialização da cibercultura.

Deste modo, para compreender o significado de cibercultura é necessário que façamos um breve relato de um dos elementos que potencializou esta nova organização social: as tecnologias de rede - TR. As TR têm um papel muito relevante na cibercultura, é através delas que esta nova dinâmica social pode se manifestar de forma plena. Uma especificação mais técnica das redes é definida por Castells quando as especifica como um "conjunto de nós interconectados", cujas principais características são a "flexibilidade e adaptabilidade" (2003, p. 7), mas esta é uma explicação básica do que realmente as tecnologias de rede representam e o alcance que possibilitam.

Considerando as características das TR, cada indivíduo presente na rede assume o papel de potencial autor e co-autor, conseqüentemente um nó na trama, onde suas ações têm o poder de influenciar o resultado final do processo comunicacional. Juntamente com as TR, uma nova forma de comunicação se instaurou na sociedade, uma forma contrária a tradicional lógica broadcast, baseada em uma organização umpara-todos, uma forma que explora a bidirecionalidade dos meios de comunicação e, conseqüentemente, a sua não-linearidade . Ou seja, as TR possibilitam uma participação do usuário no contexto no qual ele está inserido, impulsionando-o a superar possíveis posturas de passividade no qual ele se encontrava. 
Uma vez que esta estrutura comunicacional multidirecional acontece em sua maior parte no universo digital, a inclusão digital ganha uma nova relevância em relação a seu antigo conceito. Para que se possa entender a real importância da inclusão digital na sociedade, é fundamental relembrar que os indivíduos necessitam vivenciar uma cultura de rede, que, para Teixeira deve buscar "uma apropriação diferenciada, pautada na criticidade, na criatividade e na autoria" (2006, p. 30), onde cada sujeito possa assumir atitudes pró-ativas, em um sentido que propicie a interatividade e a participação, para que as características das tecnologias de redes, como a colaboração e a hipertextualidade, possam ser experimentadas.

Este modelo de interatividade potencializado pela TR, onde não há um indivíduo que retenha toda a informação para si próprio, está ficando cada vez mais visível e difundido na sociedade contemporânea. As TR pressupõem a existência de múltiplas conexões e estas, por sua vez, organizam-se em uma dinâmica multidirecional. Atualmente, a estrutura que mais parece se adequar a esse perfil é a Internet, como uma organização democrática que possibilita dar voz a qualquer indivíduo, permitindo processos de pensamento coletivo e a construção conjunta de conhecimento.

As TR têm influência fundamental na potencialização dos processos de coautoria, uma vez que permitem um contato direto e livre entre os diversos indivíduos presentes no mesmo cenário, independente do lugar físico onde se encontrem, possibilitando assim a democratização do espaço e da informação, evidenciando cada vez mais processos de inteligência coletiva.

Como conseqüência desta influência exercida sobre os processos de co-autoria, surge uma movimentação que tem como suporte as possibilidades que as TR oferecem, trata-se do software livre. O software livre é definido como "qualquer programa de computador que pode ser usado, copiado, estudado, modificado e redistribuído sem nenhuma restrição" (Free Software Fundation, 2008).

Nesta conceituação a filosofia que sustenta o movimento do software livre não esta claramente descrita. Esta filosofia é muito mais voltada para questão de liberdade do que de valor financeiro ou de estrutura técnica. Para entender o conceito é necessário pensar em liberdade de expressão e não em software gratuito.

Esta Filosofia estabelece um pensamento democrático que prima pela liberdade de conhecimento e expressão, instituindo assim a cultura Copyleft, que segundo Lemos (2004), se opõe ao termo Copyright, trazendo o sentido de uma livre transformação de obras com processos de adição e modificação criativa, mantendo a característica livre do mesmo, ou ainda, a apropriação crítica e coletiva de trabalhos.

\subsection{Kelix}

Com a chegada da tecnologia, que no princípio estava nas mãos de cientistas, estudantes e pesquisadores, a moeda universal passa a ser a informação que, de acordo com Amilton, é " um bem comum distribuído como insumo para o progresso científicocultural de todos os interessados" (MARTINS, 2003a, p.2). Com o advento e popularização das tecnologias, somando-se à informação que passa a ser considerada uma moeda importante no mundo globalizado, não participar deste processo de partilha de informações e de construção do conhecimento representa um processo exclusivo que acentua ainda mais as diferenças sociais. 
Neste sentido, processos de inclusão digital se revestem de extrema importância no cotidiano dos indivíduos. Entretanto, é necessário que se supere a concepção de que inclusão digital disponibilizar computadores conectados à internet, pois tal concepção ignora que estas tecnologias contemporâneas "oferecem a possibilidade de superação do imperativo da tecnologia hegemônica e paralelamente admitem a proliferação de novos arranjos, com a retomada da criatividade". (SANTOS, 2004, p. 81) .

Deste modo, o software livre se destaca como uma materialização dos paradigmas impulsionados pelas TR, por ser uma alternativa para a criação, a colaboração, a independência tecnológica e cultural. Segundo Sérgio Amadeu, "é baseado no princípio do compartilhamento do conhecimento e na solidariedade praticada pela inteligência coletiva conectada na rede mundial de computadores". (SILVEIRA, 2003, p. 36).

Assim é possível também apontar para a incoerência de se fomentar processos de inclusão digital com software proprietário, pois este obedece a uma dinâmica centralizadora e fechada. Embora a utilização de software livre na inclusão digital seja importante, é necessário destacar a relevância de se absorver a filosofia contida nesta modalidade de software prezando pela "horizontalidade dos processos, no estabelecimento de parcerias criativas e no reconhecimento do potencial autoral de cada nó da rede" (TEIXEIRA, 2005, p.03).

Sendo assim é fundamental o desenvolvimento de ambientes livres que incentivem a transformação de indivíduos receptores, que assumem uma postura passiva frente à rede de comunicação para indivíduos participantes e conectados na rede, transformando-se em nós ativos e que colaboraram com os processos correntes. Com base neste contexto conceitual, suporte do software livre Kelix ${ }^{1}$, tornou-se uma solução tecnológica livre para atender a demanda de softwares educativos para a formação de cidadãos críticos, participativos e produtores de conhecimento.

O Kelix, desenvolvido pelo curso de Ciência da Computação da Universidade de Passo Fundo, está sendo utilizado desde 2004 nas oficinas do Mutirão pela inclusão digital e cidadania promovidas pela UPF e nos laboratórios de informática das escolas municipais de Passo Fundo.

O Kelix tem como finalidade, proporcionar um sistema operacional para ser utilizado em escolas e oficinas de inclusão digital que tivessem como premissa os ideais da inclusão digital e do software livre, a produção e disseminação de conhecimento e a lógica das redes. Como um dos resultados desta fusão, esperava-se uma quebra de barreiras impostas pelos softwares proprietários que limitam a interação dos usuários a utilização de recursos previamente estabelecidos.

Dentre estes recursos, pode-se destacar os Objetos de Aprendizagem, que constituem-se como uma manifestação das articulações potencializadas pela cibercultura e pelo movimento colaborativo do software livre.

1 Mais informações em TEIXEIRA, A. C. ; MARTINS, A. R. Q. ; TRENTIN, M. . Kit Escola Livre: A indissociabilidade entre inclusão digital e software livre na sociedade contemporânea. In: Simpósio Brasileiro de informática na Educação, 2006, Brasília. Anais do XVII Simpósio Brasileiro de Informática na Educação. Brasília : Gráfica e Editora Positiva LTDA, 2006. v. I. p. 155-164. 


\section{Objetos de aprendizagem}

Existe uma relativa dificuldade em validar o autor e a data da criação do termo OA. Certos autores definem Wayne Hodgins, como o primeiro a utilizar o termo em 1994. Segundo estes autores, a primeira definição do conceito ocorreu em 1994, no título do grupo de trabalho do Computer Education Management Association - CEDMA chamado de "Arquiteturas de Aprendizagem, API's e Objetos de Aprendizagem" (WILEY, 2001, p.4).

Existem diferentes conceituações do termo OA. Alguns se baseiam nas características e propriedades dos OA, outros se baseiam nos elementos que compõe um OA. Uma das definições mais utilizadas em artigos e trabalhos acadêmicos é a da LTSC $^{2}$ da IEEE ${ }^{3}$.

Segundo a LTSC, "um Objeto de Aprendizagem é definido como qualquer entidade - digital ou não-digital - que pode ser usada, reusada ou referenciada para aprendizagem, educação e treinamento" (LTSC, 2002, p. 5). Esta definição é muitas vezes criticada pela sua amplitude, e foi gerada para permitir que qualquer material utilizado no processo de aprendizagem com o uso das tecnologias possa ser considerado um OA. Destaca-se o fato que o LTSC pode considerar elementos não-digitais como um OA.

Também é conveniente trazer o conceito definido pela Wisconsin Online Resource Center que diz “(...) uma nova forma de pensar sobre a aprendizagem de conteúdos(...) e são segmentos de aprendizagem muito menores que cursos módulos ou unidades" (2000, p.21). Esta definição foi criada levando em consideração algumas das características que os OAs devem conter.

Entretanto, o pesquisador David Wiley define um OA como “(...) qualquer recurso digital que pode ser reusado para suportar a aprendizagem" (WILEY, 2000, p .23). Podemos perceber que nesta definição o autor se baseou no conceito de orientação a objetos da Ciência da Computação, que prevê a criação de objetos para reutilização em diferentes contextos. Segundo o autor, esta é a idéia que fundamenta os OAs, ou seja, um projetista educacional pode construir pequenos componentes que podem ser reutilizados diversas vezes em diferentes contextos de aprendizagem.

$\mathrm{Na}$ visão de Wiley sobre os OAs destacam-se alguns fatores como, por exemplo, a exclusão da conceituação dos OAs não-digitais, que são defendidos pela LTSC; a presença da característica da reutilização e combinação; e a diversidade dos tamanhos, onde pode-se encontrar um OA extremamente pequeno, como um com tamanho considerável.

A forma de concepção dos OAs tem uma relação intimamente ligada com o paradigma da orientação a objetos amplamente utilizado na ciência da computação. Este paradigma pode ser entendido como uma forma de representar computacionalmente entidades reais em forma de objetos, uma definição mais técnica para objeto seria uma unidade dinâmica, composta por uma estrutura de dados e um comportamento.

2 Learning Technology Standards Committee, mais informações em: http://ieeeltsc.org/

3 Institute of Electrical and Electronics Engineers, mais informações em: http://www.ieee.org/ 
Deste modo, uma comparação destes dois conceitos se faz necessária para que possamos assimilar esta ligação entre os paradigmas. Assim, logo podemos comparar um OA como um objeto da orientação a objetos, e sobre o qual se pode aplicar características que são comumente utilizadas no paradigma da programação orientação a objetos.

As características que um OA carrega podem ser resumidas em quatro características principais: a reusabilidade, a agregação, a identificação, através de metadados e a interatividade. É importante destacar que estas características não são consenso, sendo que várias características podem ser atribuídas a um OA. Neste trabalho foram escolhidas por serem citadas várias vezes na literatura.

Assim, a primeira característica que será explorada neste trabalho é a reusabilidade. Ela é responsável por fazer com que a ligação com o paradigma da orientação a objetos seja reforçada. Através dela uma poderosa ferramenta dos OA é possibilitada, a reutilização em diferentes contextos de aprendizagem.

Outra característica de suma relevância para os OAs é a interatividade. Esta propriedade pressupõem que o usuário do OA deve encontrar neste meios para interagir com o conteúdo ou conceito sobre o qual o OA aborda.

Quanto maior a possibilidade de um OA ser integrado a outro, formando assim uma estrutura maior, maior sua capacidade de agregação, o que também figura como uma característica. Por sua vez, uma das características mais importantes dos OAs são os metadados, ou dados sobre dados, que funcionam de forma semelhante a um catálogo de biblioteca.

Eles fornecem informações sobre um determinado recurso, promovendo a interoperabilidade, identificação, compartilhamento, integração, utilização, reutilização, gerenciamento e recuperação dos mesmos de maneira mais eficiente. São dados descritivos que podem informar sobre o título, autor, data, publicação, palavras-chave, descrição, localização do recurso, entre outros.

Os metadados podem ser comparados a uma espécie de rotulagem que descreve o recurso, seus objetivos e características, mostrando dados como a data de criação, o modo que foi encontrado, o autor, por quem o recurso foi armazenado e como ele esta formatado, segundo De Marchi (2005), metadados são essenciais para entender o recurso armazenado, eles descrevem informações semânticas sobre o mesmo.

Sendo assim, a relevância da implementação de metadados em um repositório é de extrema importância, tanto para questões de organização como também para que todas as características nativas de um OA sejam preservadas.

\section{Protótipo do repositório de objetos de aprendizagem}

Com base nos conceitos previamente discutidos, é necessária uma breve explanação acerca dos conceitos apresentados com vistas à introduzir o potencial destes recursos como frutos da colaboração, da co-autoria e da descentralização do conhecimento. Para que este raciocínio englobe todos os conceitos envolvidos, foi elaborada uma proposta de construção do modelo de um repositório de objetos de aprendizagem para o projeto Kit Escola Livre da Universidade de Passo Fundo. 
Esta nova frente de ação do projeto vem como um meio de induzir a desterritorialização da comunidade Kelix, fazendo valer algumas leis da cibercultura. Devido ao fato do repositório estar na rede mundial de computadores, a possibilidade de indivíduos que tiverem disposição para colaborar é potencializada, visto que atualmente, mesmo com a conectividade oferecida pelas tecnologias de rede, o retorno das ações realizadas é limitado. Este retorno fica restrito a alguns usuários, professores interessados e alguns técnicos que simpatizam com a proposta do Kit.

Com o desenvolvimento do repositório, deseja-se criar um mecanismo de incentivo para que a comunidade em geral possa ter um acesso facilitado e efetivo ao projeto. Contudo, este acesso deve distinguir-se do simples observar onde o usuário não interage com o ambiente, e aguarda a disponibilização de novos OAs. O acesso ao repositório deve ser ativo e não-linear, fazendo com que o usuário auxilie no processo de construção do conhecimento e conseqüentemente faça parte da rede que se estabelece.

Seguindo os conceitos da cibercultura e das lógicas das redes, é indispensável que o repositório esteja disponível à qualquer pessoa, em qualquer lugar. Por isso, o projeto foi desenvolvido na forma de um site (Figura 1), hospedado em um servidor e acessível via um endereço $u r l$, acessível a partir de um browser.

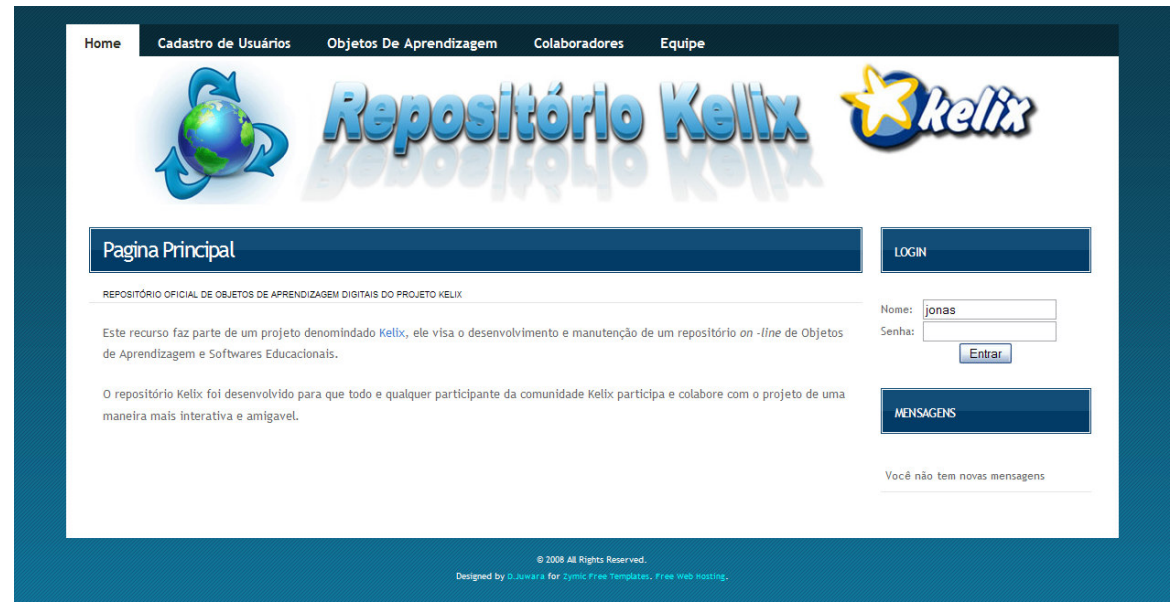

Figura 1 - Tela inicial do repositório Kelix

Para que exista um controle do conteúdo disponibilizado nas atualizações do Kelix, foram definidas algumas etapas que o objeto de aprendizagem deverá percorrer e completar para que possa ser considerado apto a ser integrado no conjunto de OAs do Kelix. Esta série de etapas foi desenvolvida para que exista uma maior garantia que o conteúdo do objeto de aprendizagem contenha realmente um valor pedagógico considerável.

O meio encontrado para avaliar tal valor foi dividir os usuários do repositório de acordo com suas habilidades. Por exemplo, o usuário com conhecimento técnico sobre empacotamento de pacotes Linux, linguagens de programação, redes, entre outras, pode, se assim desejar, ingressar no grupo de usuários técnicos. Tal categoria é dividida em vários sub-grupos especializados segundo a competência de cada colaborador. Da mesma forma, o usuário com embasamento teórico sobre as diferentes disciplinas do 
currículo escolar poderá se inscrever nos subgrupos teóricos que reflitam sua competência.

\section{Repositório}

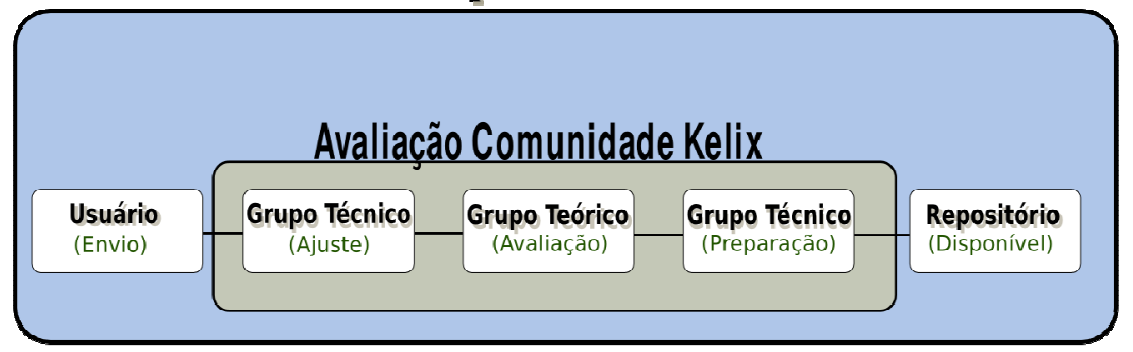

Figura 2 - Esquema de divisão de grupos

Sendo assim, as etapas pelas quais um OA deverá passar até estar disponível para fazer parte do pacote Kelix podem ser definidas em 5 grandes estágios. O primeiro estágio é o simples envio do OA pelo usuário para o repositório Kelix. Nesta etapa o usuário deverá preencher uma série de informações sobre o objeto de aprendizagem que ele está divulgando. Estas informações serão utilizadas para que os metadados do objeto de aprendizagem sejam construídos. Nesta parte do percurso os grupos não possuem nenhum tipo de envolvimento com o OA.

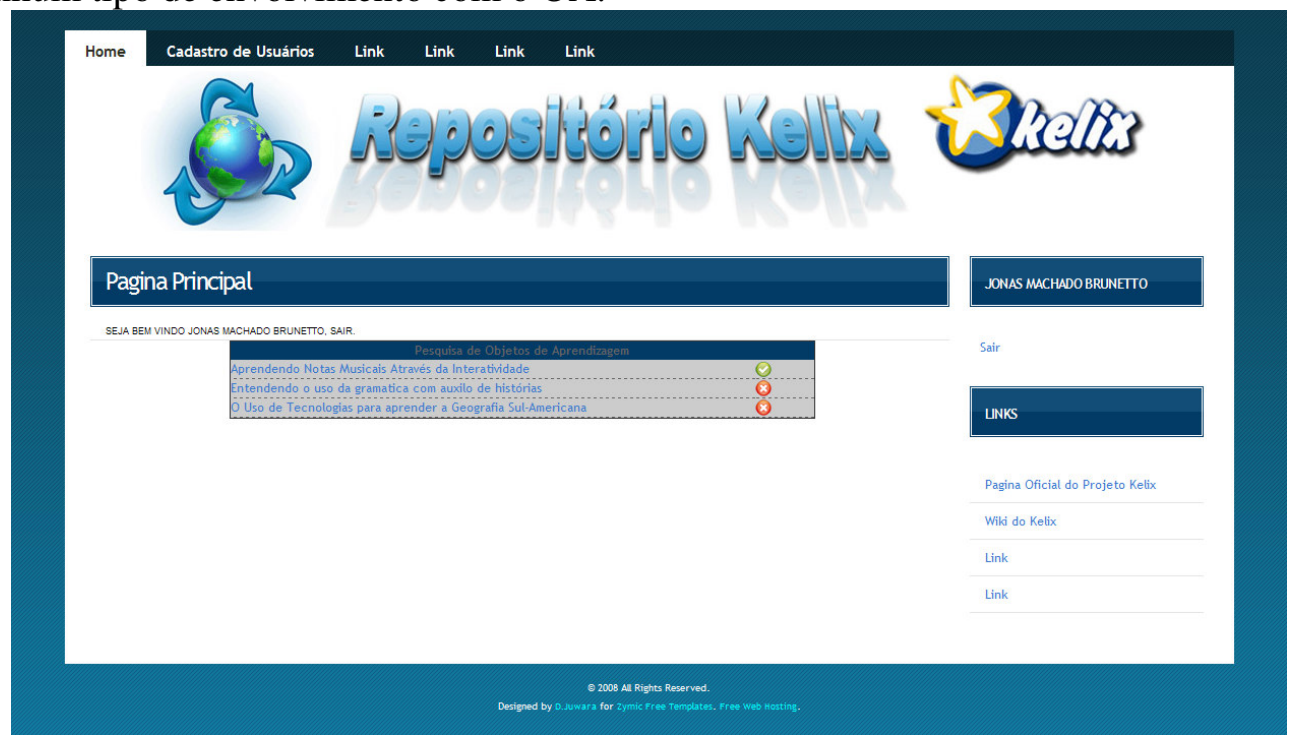

Figura 3 - Pesquisa de OA através de metadados

Após a etapa da inserção, os metadados do OA já estarão definidos, desta forma uma pesquisa através dos metadados é possível, como mostrado na Figura 3. O retorno dessa pesquisa se resume em OAs disponíveis ou bloqueados para edição ou avaliação que atendam aos parâmetros utilizados. Tais estados serão simbolizados por ícones.

$\mathrm{Na}$ próxima etapa, o OA estará disponível para que ocorra a primeira participação do grupo técnico. Será nesta etapa que o grupo técnico receberá sua primeira tarefa, que consiste em instalar o OA e avaliar suas propriedades técnicas, ou seja, examinar as tecnologias utilizadas, quais os softwares necessários para que o OA seja executado. 
Também cabe ao integrante do grupo técnico, elaborar uma pequena documentação do OA, detalhando passos de forma que uma pessoa leiga no sistema unix-like possa executá-lo. Esse tarefa foi prevista visto que a maioria dos usuários integrantes do grupo pedagógico/teórico não possuem as competências necessárias para tanto.

A partir do momento que o grupo técnico finalizar estas tarefas, o grupo pedagógico/teórico entrará em ação. Com as informações fornecidas pelo grupo técnico, o grupo pedagógico/teórico recebe a tarefa de avaliar a pertinência do conteúdo do OA. Quando o integrante do grupo teórico avaliar o objeto, ele deverá preencher um pequeno formulário onde o avaliará a partir de algumas características desejáveis a um OA, além de poder postar suas observações.

\section{Pagina Principal}

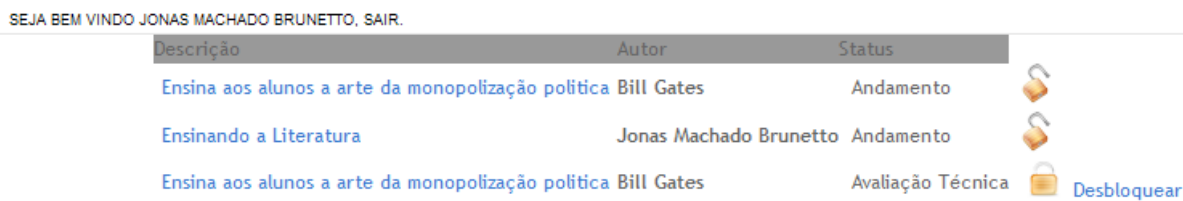

Figura 4 - Sistema de acompanhamento de OAs

Deste modo, foi criado um sistema de semáforo para indicar aos usuários o status dos OAs (Figura 4). Ao realizar uma pesquisa, o sistema de semáforo exibe a relação de OAs que atende ao resultado da consulta, com os respectivos status. Se o objeto estiver disponível, o usuário terá a possibilidade de reservá-lo, impedindo que outros usuários o utilizem.

É importante lembrar que a tramitação do $\mathrm{OA}$ entre as equipes não segue somente um sentido. O OA pode voltar ao estágio anterior se for necessário, não sendo obrigado, desta forma, a movimentar-se no processo de forma linear. Por exemplo, Se um integrante do grupo teórico avaliar o OA e chegar à conclusão que alguma funcionalidade poderia ser implementada, o objeto poderá voltar para o grupo técnico para que esta tarefa seja executada e disponibilizada novamente para avaliação do grupo teórico. Por outro lado, se o grupo teórico concluir que o conteúdo presente no OA é coerente e relevante, poderá liberá-lo para a próxima fase, a fase da integração.

Nesta fase, o OA estará com seu conteúdo e propriedades técnicas definidas e avaliadas, desta forma, o grupo técnico receberá uma nova tarefa, fazer as rotinas necessárias para que o OA passe a integrar as possíveis atualização do Kelix. Quando esta tarefa estiver completa, o próximo passo é a disponibilização do OA no painel do Kelix, de forma dinâmica, sem complicações para o usuário final. Desta forma, através desta rotina de etapas, um usuário é capaz de iniciar um processo onde a co-autoria e a colaboração são as principais forças motivadoras para o desenvolvimento de um objeto de aprendizagem relevante e que possa, de fato, auxiliar no processo de construção do conhecimento. 
Levando em consideração os conceitos que compõe a cibercultura, podemos afirmar que o repositório Kelix é uma agregação de vários destes conceitos, utilizandose deles para contribuir com o desenvolvimento do projeto Kelix, e conseqüentemente contribuindo para o movimento de inclusão digital do município de Passo Fundo.

\section{Considerações Finais}

A construção do repositório Kelix representa uma resposta a uma demanda urgente da comunidade de Passo Fundo que necessita um espaço efetivo de participação neste movimento de informatização e de qualificação da informática educativa do município.

O fato de ser a solução tecnológica de todas as escolas municipais, imprime ainda maior urgência na implementação e disponibilização de mecanismos que tornem os laboratórios de informática, espaços efetivos de construção do conhecimento, especialmente, a partir dos objetos de aprendizagem disponibilizados no Kit Escola Livre.

Entretanto, para que, de fato, se fomente a participação efetiva de todos os agentes envolvidos, postura fundamental na cibercultura, o repositório se faz, não somente necessário, mas urgente e estratégico para que os laboratórios de informática constituam-se em espaços efetivos de aprendizagem.

\section{Referências Bibliográficas}

Castells, Manuel. A sociedade em Rede. São Paulo: Paz e Terra, 2003.

DE MARCHI, A. C. B. Um ambiente de suporte a comunidades virtuais baseados em repositório de objetos de aprendizagem informal em museus. 2005. Tese (Doutorado em Informática em Educação) - PGIE, UFRGS. Porto Alegre, 2005.

Institute of Electrical and Electronics Engineers LTSC. Learning technology standards committee website. WG12: Learning Object Metadata. 2003. Disponível em: http://ltsc.ieee.org/. Acesso em out 2008.

Lemos, André; Cunha, Paulo (orgs). Olhares sobre a Cibercultura. Sulina, Porto Alegre, 2003.

;Cibercultura e Identidade Cultural. Em direção a uma cultura copyleft?. Ensaio apresentado do Fórum Cultural Mundial e no Simpósio Emoção Art. Ficial (Itaú Cultural). São Paulo, julho 2004. Disponível em: $<$ http://www.facom.ufba.br/ciberpesquisa/andrelemos/copyleft.pdf>. Acesso out. de 2008.

Martins, Amilton Rodrigo de Quadros ; MALAGGI, Vitor ; SILVA, Juliano Tonezer da. Kit Escola Livre - A formação de uma nova geração pela Liberdade Consciente. In: Fórum Internacional Software Livre, 2006, Porto Alegre.

SANTOS, Milton. AA globalização atual não é irreversível, 2004. Disponível em $<$ http://serpensar.vilabol.uol.com.br/miltonsantos.htm>. Acesso em out de 2008.

Teixeira, A. C. (2005) "Formação Docente e Inclusão Digital: a análise do processo de emersão tecnológica de professores”. Tese (Doutorado em Informática na Educação) 
- Programa de Pós Graduação em Informática na Educação da Universidade de Federal do Rio Grande do Sul, Rio Grande do Sul, 2005.

WILEY, D. A. Learning object design and sequencing theory. Brigham Young University. $2000 . \quad$ Disponível em: http://davidwiley.com/papers/dissertation/dissertation.pdf . Acesso em out de 2008.

WILEY, D. A. Conecting learning objects to instructional theory: A definition, a methaphor and a taxonomy. The Instructional Use of Learning Objects. Wiley, D. (Ed.). 2001. Disponível em: http://www.reusability.org/read/chapters/wiley.doc .2001. Acesso em out de 2008 .

Wisconsis on-line resource center. What are learning objects? 2000 